\title{
Oil Price Based Trading And European Industry Sector Stocks
}

Michael Soucek, European University Viadrina, Germany

\begin{abstract}
This study shows that the relationship between oil price changes and European stock market is significant and vary in relation to individual industry sectors. The oil price changes exhibit significant Granger causality for majority of European industry sector stock returns, but no cointegration could be determined for the price series. The results are proved to be economically exploitable for trading strategies. The trading rule based on the bivariate $\operatorname{VAR}(p)$ model for forecasting future stock returns significantly outperforms the buy-and-hold strategy in term of expected return and risk. It yields large Sharpe ratios and significant positive Jensen's alpha for both weekly and monthly data.
\end{abstract}

Keywords: Oil Prices; Stock Returns; European Industry Sectors; VAR; Cointegration; Trading Strategy; Efficient Market Hypothesis

\section{INTRODUCTION}

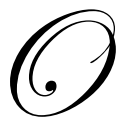

il prices and their effect on various macroeconomic variables is an object of ongoing research in academic literature. The impact of changes in oil price on equity prices is still a relatively young field of research, but particularly in the last few years, the number of studies on this topic has increased remarkably. According to the theory, the value of a firm equals the discounted sum of the expected future cash flows. The cash flows themselves are assumed to be influenced by a company's relative economic condition, which is driven by, for instance, interest rates, exchange rates, income, revenue or production costs as well as diverse macroeconomic factors such as GDP or prices of resources. Motivation for analyzing the hypothesis about the link between the oil and stock market is obvious, since oil is one of the important inputs for almost all kinds of industries. The aim of this paper is twofold. First, it analyzes the impact of oil prices on the European stocks prices and returns within individual industry sectors. It has been verified that there is a statistically significant impact of oil price changes on the majority of industry sector stock returns in Europe, as well as on the aggregated European stock market index. Nevertheless, considering the price time series indicated no cointegration relationships, which implies a lack of a common stochastic trend and long term stable relationship. It could have been shown that the impact of oil return on stock return varies for different European industry sectors. The stocks in the oil \& gas sector, for instance, seem to absorb the information from the energy market much faster than in other industries, which supports the findings of Driesprong et. al., (2008) and Nandha \& Faff (2008) published for other markets. The second aim of this paper is to draw possible implications for market participants. Most studies on the relationship between oil and stock prices conclude by making a statement about the connection and causality between the time series data. While the majority of recent research studies agree on the existence of a link between oil price and stock price, it is still possible that even though the results are statistically significant, they are not economically exploitable. This paper introduces a trading strategy based on the underlying vector autoregressive (VAR) model containing oil returns as a predictor of future stock returns. For monthly and weekly returns, a trading technique based on a bivariate VAR model can provide investors with abnormal returns and has comparably favorable riskreturn characteristics relative to the buy-and-hold policy. This trading strategy outperforms the market return measured by Jensen's alpha and Sharpe ratio, and exhibits significantly lower standard deviation of its returns when compared to the market index. To confirm the validity of our results, the study contains a necessary robustness check of the trading rule itself, which has been frequently omitted in the literature. 
The results of the study provide not only valuable information for investors, hedgers and other market participants but also contribute to the ongoing research on market efficiency. Fama (1970) provides the textbook definition of an efficient market, which has been broadly cited in the literature: "A market in which prices always fully reflect available information is called efficient." A more detailed definition has been developed by Jensen (1978): A market is efficient with respect to an information set, if it is impossible to make economic profits by trading on the basis of this information set. Because economic profits are defined as risk-adjusted returns after deducting transaction costs, Jensen's definition implies that the efficient market hypothesis (EMH) can be tested by considering the net profits and risk of trading strategies based on available information. A good survey of the results of a technical analysis used for testing the efficiency market hypothesis, as well as a discussion on the theoretical concepts related to technical trading is provided by Park \& Irwin (2007). In this paper, information from the oil market was used to trade equity, and the obtained results at least question the hypothesis that the European market satisfies the requirements of a semi-strong efficient market. Nevertheless, this paper does not aim to reject the efficient market hypothesis itself. Furthermore, it is trying to open a discussion on economical exploitability of cross-market relationships. Further research on this topic is necessary. The paper is structured as follows. In section 2, the empirical methodology for investigating the relationship between the series is introduced. In section 3, the data and the results relating to the link between oil and stock prices are discussed, and a conclusion is reached. Section 4 features the design and implementation of a trading technique based on the bivariate VAR model and analyzes the out-of-sample results. Section 4 also contains various robustness checks. Section 5 concludes the paper.

\section{LITERATURE REVIEW}

Many researchers have brought a broad perspective to analyzing the relationship between oil prices and economic variables such as GDP or production in detail. Hamilton (1983) and Gisser \& Goodwin (1986) conclude that oil price shocks might impact the future development of the macroeconomy and could be a cause for economic recession. Much research on the effect of oil prices on real activity has been influenced by Hamilton's paper, and his findings have been elaborated on and confirmed by many studies (Mork 1989, Lee et. al., 1995, Hooker 1995). The impact of changes in oil price on the equity prices is still a relatively young field of research. Jones \& Kaul (1996) test the impact of oil prices on four developed markets using the cash-flow dividend model, and find significant negative correlation to the U.S. stock market. Huang et. al., (1996) discuss the relationship between daily oil futures returns and daily U.S. equity returns using a vector autoregression approach and find that oil futures returns do affect some individual oil company stock returns. Nevertheless, the authors could not prove that futures returns have much impact on market indices such as the S\&P 500. More recent studies do tend to support the hypothesis that the link between national stock indices and oil price time series is significant (Driesprong et. al., 2008; Basher \& Sadorsky 2006; Park \& Ratti, 2008; Sadorsky, 1999). There exist only a few studies analyzing the impact on the individual industry sectors. Al-Mudhaf \& Goodwin (1993) considered 29 oil companies on the New York Stock Exchange and found a positive impact of oil price shocks on returns for firms with significant assets in domestic oil production. Sadorsky (2001) show that an increase in oil prices leads to higher prices of oil and gas companies in Canada. A very recent study by Nandha \& Faff (2008) uses a multifactor market model to describe the impact of oil prices on 30 world sector indices and finds a rise in oil prices has a detrimental effect on stock returns in all analyzed sectors other than mining and the oil and gas industry. Literature considering European industries is rather scarce. Oberndorfer (2009) discusses the impact on the prices and volatility in the energy sector in Europe, while another very recent study by Arouri \& Nguyen (2010) uses a market model to analyze the impact of unexpected shocks in oil prices on industry indices, and suggests that the obtained results can be used to improve portfolio diversification.

\section{METHODOLOGY}

\section{VAR Model}

Based on Sims (1980)'s findings the relationship between two stationary time series can be empirically investigated by the vector autoregressive model. In fact, this approach has often been used in academic literature to evaluate the relationship between stock and oil prices. In the most basic bivariate case, a VAR consists of two equations and can be written as follows: 


$$
\begin{aligned}
& y_{t}=c_{1}+\sum_{p=1}^{P} \alpha_{1 p} y_{t-p}+\sum_{p=1}^{P} \beta_{1 p} x_{t-p}+\varepsilon_{t} \\
& x_{t}=c_{2}+\sum_{p=1}^{P} \gamma_{1 p} x_{t-p}+\sum_{p=1}^{P} \delta_{1 p} y_{t-p}+\varepsilon_{t}
\end{aligned}
$$

where $c_{1}$ and $c_{2}$ denote the constants and $\varepsilon_{t}$ is white noise error term. $y_{t}$ and $x_{t}$ are the observations of two stationary time series, while $p$ represents the used lag length. In the following study, one of the equations describes the oil price dynamics, while the other represents the analyzed equity index movements. One of the advantages of using a VAR is that in doing so, it is not necessary to provide prior assumptions about which variables are exogenous and which are endogenous. In this model, all variables are treated as endogenous. Each variable depends on the lagged values of all other variables in the system. Because the model is sensitive to the choice of the laglength, the appropriate number of lags is usually estimated using the Akaike Information Criterion (AIC) or Schwarz Bayesian Criterion (SBC). In the case of non-stationary time series, which are integrated of order one, i.e. (I(1)), the VAR in first differences can be estimated, and conventional asymptotic theory can be used for hypothesis testing. In addition, Engle \& Granger (1987) proposed that a linear combination of non-stationary time series can be stationary. This is the case in which cointegration relationships exist; i.e., the time series have a common stochastic trend. Such a trend implies long-term stable relationships among the time series. If the cointegration vector is indicated, the VAR model will be extended by an error correction term to the vector error correction model (VECM).

\section{EMPIRICAL RESULTS}

\section{Data}

This study considers monthly data from January 1990 to September 2010. The Morgan Stanley Capital International (MSCI) European reinvestment index is used to track the development of the European equity market. To describe the movement in the industry sector stocks, ten Datastream indexes provided by Thompson Datastream Database are employed: Oil \& Gas, Basic Materials, Industry, Consumer Services, Consumer Goods, Health Care, Telecommunication, Technology, Financial Services and Utilities. All prices have been linearized with a natural logarithm and calculated at the end of the month. The log returns are defined as a difference in $\log$ prices. The consideration of monthly prediction interval is assumed to be common practice among numerous institutional investors; this choice is consistent with the findings of Ghysels et. al., (2005), for instance, who suggest that the monthly frequency describes the "best balance between sample size and the signal-to-noise ratio". Later in the paper, robustness checks based on weekly prices are provided as well. The weekly returns are calculated on Wednesday of each week, to avoid the impact of higher trading volumes on Monday and Friday. The one-month European Interbank Offering Rate (EURIBOR) and one-week EURIBOR is used as a proxy for the risk free rate in the period after 1999. Before 1999, Frankfurt Interbank Offering Rate (FIBOR) was used. The Brent type crude oil is the oil price proxy, given that oil production in Europe is priced relative to this type. The Brent oil prices as well as the analyzed stock returns are expressed in Euros.

\section{Unit Root Test and Cointegration}

The first step is to investigate the stationarity of the observed univariate time series, the existence of which is the key assumption of the OLS based VAR estimation. Augmented Dickey-Fuller (ADF) test for unit roots is adopted to evaluate the property. For all of the time series, I run following regression:

$$
\Delta y_{t}=\alpha+\beta t+\gamma y_{t-1}+\sum_{p=1}^{P} \Delta y_{t-p+1}+\varepsilon_{t},
$$

where the optimal lag $p$ is based on the AIC. The null hypothesis of the ADF-test is $\gamma=0$. If the variable is integrated of order one, $y_{t-1}$ provides no relevant information for predicting $y_{t}$ outside of that already obtained in 
$\Delta y_{t-p}$. In such a case, the null hypothesis cannot be rejected; i.e., the time series $y$ has a unit root. The t-values are compared with the Dickey-Fuller (DF) t-values and summarized in Table 1. As the results indicate, all log price series are integrated of order one, which implies that the log return time series are stationary. The result is in line with the general accepted fact that the price series tend to have a time trend, but stock return time series are stationary. For European industry sectors, f.e. Arouri \& Nguyen (2010) and Oberndorfer (2009) obtain same results.

Table 1: Unit Root Test and Granger causality

\begin{tabular}{|c|c|c|c|c|c|c|c|}
\hline & \multicolumn{2}{|c|}{$\mathbf{I}(\mathbf{0})$} & \multicolumn{2}{|c|}{$\mathbf{I}(\mathbf{1})$} & \multicolumn{3}{|c|}{ Granger causality } \\
\hline Index & Lags & DF & Lag & DF & $\mathbf{O} \rightarrow \mathbf{S}$ & $\mathbf{S} \rightarrow \mathbf{O}$ & Inst. Caus. \\
\hline MSCI Eur & 3 & -1.45 & 2 & -7.69 & $4.79^{\text {*** }}$ & $2.92^{\text {** }}$ & 0.05 \\
\hline Oil \& Gas & 2 & -1.35 & 1 & -10.20 & 0.80 & $4.37^{\text {** }}$ & $30.80^{* * * *}$ \\
\hline Basic Met & 6 & -3.22 & 5 & -6.92 & 0.84 & $8.86^{* * * *}$ & 2.14 \\
\hline Cons Gds & 2 & -2.84 & 1 & -9.87 & $4.24^{\text {** }}$ & 0.79 & 0.38 \\
\hline Industry & 4 & -2.66 & 3 & -6.39 & $3.05^{* *}$ & $3.08^{* *}$ & 0.00 \\
\hline Cons Serv & 2 & -1.58 & 1 & -10.20 & $2.95^{\text {** }}$ & $2.13^{*}$ & 0.05 \\
\hline Health & 2 & -1.22 & 1 & -9.75 & 0.40 & 0.05 & $2.73^{*}$ \\
\hline Telcom & 5 & -1.42 & 4 & -6.34 & $4.85^{\text {** }}$ & 1.39 & 0.31 \\
\hline Utility. & 2 & -1.26 & 1 & -9.93 & 1.46 & 0.88 & 0.11 \\
\hline Financial & 5 & -1.70 & 4 & -5.83 & 1.80 & $2.98^{* *}$ & 0.22 \\
\hline Tech & 4 & -1.25 & 3 & -6.76 & $4.80^{* * *}$ & $2.72^{* *}$ & 0.31 \\
\hline
\end{tabular}

Note: The corresponding Dickey Fuller t-values for lag one an 5\% significance level is -3.24. The highest DF t-value is -3.94 for lag of four. Instanenous causality has been tested using $\chi^{2}$ Test statistics. The null hypothesis is no Granger causal relationship. $*$ denotes significance on the $10 \%$ level, ** on $5 \%$ level and *** on $1 \%$ level. The lag length has been chosen using AIC.

Table 2: Cointegration

\begin{tabular}{|c|c|c|c|}
\hline Index & $H_{0}$ & $\chi^{2}$-test & $5 \%$ crit. \\
\hline \multirow[t]{2}{*}{ MSCI Eur } & $r \geq 0$ & 17.85 & 25.32 \\
\hline & $r \geq 1$ & 3.17 & 12.25 \\
\hline \multirow[t]{2}{*}{ Oil \& Gas } & $r \geq 0$ & 18.18 & 19.99 \\
\hline & $r \geq 1$ & 5.98 & 9.13 \\
\hline \multirow[t]{2}{*}{ Basic Mat } & $r \geq 0$ & 24.90 & 25.32 \\
\hline & $r \geq 1$ & 11.01 & 12.25 \\
\hline \multirow[t]{2}{*}{ Cons Gds } & $r \geq 0$ & 10.36 & 19.99 \\
\hline & $r \geq 1$ & 1.94 & 9.13 \\
\hline \multirow[t]{2}{*}{ Industry } & $r \geq 0$ & 20.24 & 25.32 \\
\hline & $r \geq 1$ & 5.26 & 12.25 \\
\hline \multirow[t]{2}{*}{ Cons Serv } & $r \geq 0$ & 18.22 & 25.32 \\
\hline & $r \geq 1$ & 4.26 & 12.25 \\
\hline \multirow[t]{2}{*}{ Health } & $r \geq 0$ & 18.95 & 19.99 \\
\hline & $r \geq 1$ & 5.65 & 9.13 \\
\hline \multirow[t]{2}{*}{ Telcom } & $r \geq 0$ & 17.64 & 25.32 \\
\hline & $r \geq 1$ & 4.18 & 12.25 \\
\hline \multirow[t]{2}{*}{ Utility } & $r \geq 0$ & 14.60 & 25.32 \\
\hline & $r \geq 1$ & 3.19 & 12.25 \\
\hline \multirow[t]{2}{*}{ Financial } & $r \geq 0$ & 18.42 & 25.32 \\
\hline & $r \geq 1$ & 3.22 & 12.25 \\
\hline \multirow[t]{2}{*}{ Tech } & $r \geq 0$ & 20.34 & 25.32 \\
\hline & $r \geq 1$ & 3.06 & 12.25 \\
\hline
\end{tabular}

Note: The optimal length has been estimated using AIC and is listed in Table 1. The results for maximum eigenvalue allow the same interpretation. 
Engle and Granger (1987) proposed that a linear combination of non-stationary time series could be stationary. As explained above, this is the case when the two time series contain a common stochastic trend; i.e., there exists long-term stable relationships among the time series. If a common stochastic trend is indicated, classic VAR in first differences does not describe the relationship between the time series correctly. Vector error correction models should be estimated instead. To judge whether the cointegration relationship between the log price series exists, the maximum likelihood procedure based on Johansen (1988) and Johansen (1991) will be employed. This procedure detects the number of cointegrating vectors present in non-stationary time series. The $\operatorname{VAR}(p)$ model from 1 and 2 can be re-written using matrix notation as

$$
\Delta Y_{t}=\mathbf{c}+\Pi Y_{t}+\sum_{i=1}^{P-1} \Gamma_{i} \Delta Y_{t-i}+\boldsymbol{\varepsilon}_{t}
$$

$Y_{t}$ is $2 \times 1$ vector of observations from analyzed non-stationary time series $y$ and $x . \Delta$ describes the first difference in the observations. $\Gamma_{i}$ is a coefficient matrix and $\varepsilon_{t}$ is a vector of innovations. The trace-test and maximum eigenvalue verify, the existence of a non-zero vector in $\Pi$. If this is the case, the stationary long-run relationship between the series is implied. The null hypothesis for the trace test is the number of cointegration vectors; i.e., if the rank of $\Pi$ in equation 4 is $r \leq i$, the null hypothesis for the eigenvalue test is $r=i$. For the $\log$ price time series, which are not stationary according to the ADF test, the results of the trace test are summarized in Table 2. For all pairs of time series, the evidence is the same using a testing procedure based on maximum eigenvalues. The table was omitted to save space. In the end, no cointegration relationship on the 5\% significance level could be indicated. This result is not surprising given that the evidence for cointegration relationship between oil and equity prices in the academic literature is mixed. The results tend to vary for different data frequency, different markets, industries, and for different time periods. In sum, the monthly industry-specific log stock prices are integrated of order one and not cointegrated with the log prices of Brent oil, which implies that there exists the possibility to investigate the relationship using VAR in first differences. Since the first differences of the log prices are nothing else but the returns, we could imply that link between the returns on the oil and returns on equity could be described using a bivariate $\operatorname{VAR}(p)$ model.

\section{Granger Causality}

Analysis of the estimated coefficients themselves sometimes reveals uninteresting results. Bivariate VAR models are in most cases used to test Granger causality and to determine whether lags of one variable help to explain the current value of some other variable. The null hypothesis of the test is that the variable $y$ does not Granger cause variable $x$ and vice versa. To verify causality, the unrestricted equation 1 and equation 1 under the restriction $\beta=0$ are estimated and then F-Statistics is used to test for the equality of both models. If the explanatory power differs, it could be concluded that $x$ Granger causes $y$. Because the relationship is not symmetric, Granger causality in one direction does not imply causality in the other. The test results for the causality relationships are summarized in Table 1. Additionally, the data have been tested for instantaneous causality. If, in period $t$, adding $x_{t+1}$ to the information set improves the forecast of $y_{t+1}$, there is instantaneous causality between the two variables (Lütkepohl 2005). Because this concept of causality is symmetric, we speak about instantaneous causality between $x_{t}$ and $y_{t}$, and deem the direction irrelevant.

The log price changes of Brent oil Granger cause consumer services sector stock returns in Europe as well as stock returns in consumer goods, telecommunications, technology, industry sectors and MSCI Europe index itself. Conversely, stocks in the following sectors exhibit Granger causality to the returns on the oil market: oil \& gas, basic material, industry, consumer services, financial services and technology, as well as the MSCI Europe. In the case of oil \& gas sector stocks, while we are unable to observe an impact of the past monthly oil returns, the instantaneous causality seems to be very strong. This supports the prior research of, for instance, Driesprong et. al., (2008), who showed that while stock markets in general tend to underreact to information from the energy market, oil-related stocks usually tend to react faster. Another sector presumed to be strongly related to the oil price changes 
is industry. In this case, bidirectional Granger causality is observable, as in the case of European MSCI index, consumer services, and technology. While the economic explanation for the results in the consumer services and goods sector is unclear, the link between the technology sector and oil price is not surprising. The sector results support findings similar to those in the literature for other countries, observing varying impact of the oil price information on different industries. The results verify the generally accepted fact that the oil \& gas industry absorbs information faster comparing than other industries (Driesprong et. al., 2008, Nandha \& Faff 2008) in the case of the European equity market. The obtained statistically significant link to the overall stock indices is also in line with common findings.

\section{VAR based Trading}

Studies on the link between oil prices and stock markets typically end with a statement concerning the causal relationship between the two, concentrating on the strength, direction and statistical significance of the relationship. Literature on the implications for investor decisions or portfolio diversification is rather scarce. Related to data used in this paper, Arouri \& Nguyen (2010) shows that diversification with oil spot price-based products can improve the risk-return profile of stock portfolios. While the majority of recent research studies agree about the existence of the link between oil price and stock price, it is possible that while the results are statistically significant, they are not economically exploitable. Existing literature pays little attention to this fact. Driesprong et. al., (2008) in a recent paper shows, that a simple trading rule based on one-month lagged oil returns yields a better risk-return profile than a buy-and-hold strategy, and shows that the economic significance of the oil price shocks in the sense of Hong et. al., (2007) is stronger than for other possible predictors, such as interest rates or dividend yields. This paper expands upon

the idea of exploiting the relationship between the two markets and shows that a bivariate-VAR-based trading rule strongly decreases the risk of an investment and yields abnormal returns for the investor in the case of European equity market and diverse industry sectors stocks. The results are robust and valid for weekly and monthly returns over the last twenty years.

\section{Trading rule}

The trading strategy is to exploit one-step-ahead forecasts of the stock returns based on the movement in the oil spot prices. To obtain the forecasts, bivariate rolling $\operatorname{VAR}(p)$ model was employed:

$$
\tilde{y}_{t+1}=\hat{c}_{1}+\sum_{p=0}^{P-1} \hat{\alpha}_{p} y_{t-p}+\sum_{p=0}^{P-1} \hat{\beta}_{p} x_{t-p}
$$

$y_{t-p}$ stands for the index stock returns, and $x_{t-p}$ describes past changes in the prices of Brent type oil. $\tilde{y}_{t+1}$ is the one-period-ahead predicted stock index return. Parameters $\hat{\alpha}$ and $\hat{\beta}$ are estimated from the 48 month rolling insample window. Optimal lag length $p$ has been estimated for every single rolling window using AIC. The trading rule is designed to generate a signal for the investor to invest in the equity market or EURIBOR bonds each month. If the forecasted equity market return $\tilde{y}$ is greater than the current risk-free rate, it generates a signal to invest in the equity market; otherwise, it signals that the investor should invest in bonds. Similar trading rules have been used in various studies on technical trading (Park \& Irwin 2007). This strategy can be easily implemented using index futures or another instrument tracking the index such as an exchange traded fund (ETF). Especially for the industry indices no futures are usually traded, but the possibility to track the index with an ETF exists. Transaction costs are assumed to be $0.1 \%$ which is consistent with the literature on technical trading. The returns were compared with the returns acquired by holding an index-related product.

The risk and return characteristics of the strategy is discussed by considering Sharpe ratio and standard deviation comparison. Furthermore, CAPM-based Jenson's alpha was estimated running following regression: 


$$
r_{t}^{O S}-r_{f}=\alpha+\beta_{i}\left(r_{t}^{\text {Index }}-r_{f}\right)+\varepsilon_{t},
$$

where $r_{t}^{O S}$ describes the return of the oil price based strategy in time $t$ and $r_{t}^{\text {Index }}$ the return of the corresponding market index; this is nothing but the return of the of the buy-and-hold strategy. The estimate $\beta_{i}$ is the systematic risk of the trading strategy compared to the market return and $\alpha$ is the Jensen's alpha. To account for possible heteroscedasticity and autocorrelation (HAC) in the explanatory variables, the test statistics are calculated using Newey \& West (1987) standard errors. Descriptive statistics for the trading rule are summarized in the Table 3, the results of the regression 6 are provided in Table 4.

Table 3: Trading Strategy: Descriptive statistics

\begin{tabular}{|l|c|c|c|c|c|c|}
\hline & \multicolumn{3}{|c|}{ Buy-and-Hold Policy } & \multicolumn{3}{c|}{ Trading Strategy } \\
\hline \multicolumn{1}{|c|}{ Index } & Mean & SD & SR & Mean & SD & SR \\
\hline MSCI Europe & 3.74 & 0.048 & 0.009 & 11.67 & 0.033 & 0.215 \\
\hline Oil \& Gas & 7.05 & 0.056 & 0.057 & 10.81 & 0.047 & 0.134 \\
\hline Basic Mat. & 6.95 & 0.061 & 0.051 & 16.23 & 0.39 & 0.277 \\
\hline Cons. Gds. & 5.43 & 0.058 & 0.032 & 11.03 & 0.038 & 0.171 \\
\hline Industry & 5.42 & 0.061 & 0.030 & 13.69 & 0.041 & 0.212 \\
\hline Cons. Serv. & 3.27 & 0.051 & 0.001 & 14.61 & 0.032 & 0.293 \\
\hline Health & 5.74 & 0.035 & 0.059 & 11.21 & 0.027 & 0.246 \\
\hline Telecom & 4.03 & 0.066 & 0.010 & 16.84 & 0.047 & 0.239 \\
\hline Utility & 5.44 & 0.040 & 0.046 & 12.10 & 0.029 & 0.249 \\
\hline Financial & 2.78 & 0.063 & -0.006 & 15.12 & 0.039 & 0.251 \\
\hline Tech & 6.18 & 0.095 & 0.026 & 25.76 & 0.059 & 0.317 \\
\hline
\end{tabular}

Note: Mean is given in \% per anum. SD stands for standard deviation, SR for Sharpe ratio.

\section{RESULTS}

For all analyzed indices, VAR-based trading strategies generate higher mean returns and smaller standard deviations than the buy-and-hold policy. Using the F-Test for a comparing of variances implies that the variance of the buy and hold strategy is significantly larger that of the trading rule. Remarkably large Sharpe ratios also support the hypothesis of a more favorable risk-return relationship of the oil-based strategy compared to the buy-and-hold policy. Using the VAR-based strategy in connection with the MSCI Europe index, for instance, one could achieve $11.67 \%$ annual return, while a buy-and-hold strategy yields only 3.74\%. The Shrape ratio for the oil based trading strategy is $21.5 \%$, almost 25 times larger than the $0.9 \%$ in the case of holding the market index. Similar results can be observed for all considered industry sector related stock indices. Table 4 describes more precisely the economic significance of the trading rule. For all analyzed indices, the Jensen's alpha is significantly positive. Implementation of this strategy for the European MSCI equity index would yield on average risk adjusted $8.21 \%$ per anum more than the buy-and-hold strategy. Furthermore, beta coefficients, which measure the systematic risk of the trading strategy, are significantly smaller than one, confirming that the oil strategy is substantially less risky than investing in the market or sector index. A good trading strategy should provide reasonable signals for going in or out of the stock market. If the rule implies holding the market index related product, one should expect significant positive returns of the market index (H1). A good trading strategy should be capable of indicating the bullish market. On the contrary, if the rule implies the optimal step is to invest in bonds, one might expect a downward trend in the market index and negative returns in the equity market related product. If the return of the market index in this period is significantly positive, the trading technique is missing potential sources of additional gains. In this sense, one might expect the market returns to be less than or equal to zero in the periods following the trading strategy's sell signal $(\mathrm{H} 2)$. Columns $\mathrm{t}$ (Buy) and $\mathrm{t}(\mathrm{Sell})$ in Table 4 contain the t-values for corresponding tests. Buy is the test result for hypothesis (H1), and Sell is the test result for hypothesis (H2). For all indices, the trading strategy yields positive returns after a buy signal, and with exception of the oil \& gas and consumer goods sector, after a sell signal, the market is bearish. For the consumer sector this result may be surprising, given the previous results indicating Granger causality between changes in oil price and changes in the consumer goods-related stock index. On the contrary, the oil \& gas sector tends to absorb the information from the oil market faster than other sectors. 
Nevertheless, the Jensen's alpha, Sharpe ratio and significantly positive market returns in the buy period in these two cases indicate the trading technique's superiority to the buy-and-hold policy. It is generally remarkable that even if we unable to prove Granger causality for all analyzed pairs, the trading technique provides good results for all equity indices. A possible explanation for this is that while the causality itself was tested for the whole sample, only the relationship in the short in-sample is relevant for the trading rule. The profitability of the trading strategy indicates that the power of causality relationships could vary over different subsamples.

Table 4: Jenson's alpha

\begin{tabular}{|l|c|c|c|c|c|c|}
\hline \multicolumn{1}{|c|}{ Index } & Buy & Sell & $\alpha$ & $\mathbf{t}(\alpha)$ & $\beta$ & $\mathbf{t}(\beta)$ \\
\hline MSCI Europe & 3.09 & -2.80 & 8.21 & 3.99 & 0.48 & 6.16 \\
\hline Oil \& Gas & 2.51 & -1.15 & 4.91 & 2.19 & 0.70 & 11.46 \\
\hline Basic Mat. & 4.64 & -2.17 & 11.41 & 3.77 & 0.43 & 4.27 \\
\hline Cons. Gds. & 3.10 & -1.23 & 6.86 & 2.76 & 0.44 & 5.27 \\
\hline Industry & 3.03 & -1.84 & 9.20 & 3.14 & 0.45 & 5.09 \\
\hline Cons. Serv. & 4.98 & -3.35 & 11.37 & 6.07 & 0.44 & 6.14 \\
\hline Health & 4.54 & -3.17 & 6.46 & 3.54 & 0.611 & 6.59 \\
\hline Telecom & 3.93 & -3.24 & 13.2 & 4.38 & 0.53 & 5.47 \\
\hline Utility & 4.48 & -2.55 & 7.56 & 5.69 & 0.55 & 7.48 \\
\hline Financial & 4.21 & -2.84 & 12.09 & 4.30 & 0.42 & 5.01 \\
\hline Tech & 5.07 & -3.15 & 21.3 & 6.177 & 0.42 & 4.98 \\
\hline
\end{tabular}

Note: Jenson's alpha is given in \% per anum. The columns Buy and Sell give the t-values for Hypothesis H1 and H2.

\section{Robustness checks}

To ensure that the results are not caused by randomness, I provide various robustness checks containing sub-period analysis and variation of the in-sample period length. I verify, if the construction of the trading rule allows one to make statements regarding the power and economic significance of the $\operatorname{VAR}(p)$ based forecast. Additionally, the trading strategy is evaluated for weekly data.

\section{Trading Rule}

The trading decision is based on the comparison of the forecast generated by $\operatorname{VAR}(p)$ and risk-free rate represented by FIBOR and EURIBOR. It is theoretically possible that the signal exhibits predictive power because of expected return estimates or because EURIBOR itself has significant predictive power for the future market development. In the latter case, it would not be possible to conclude that the oil price based strategy really outperforms the market. Even if it is essential to analyze the rule when evaluating the results of the trading technique, verifying the validity of the trading rule has been frequently omitted in the literature. In this study, to prove whether or not there is predictability power of interest rates on the stock returns, I run a simple regression model

$$
r_{t}^{I}=\alpha_{i}+\beta_{i} E_{U R I B O R_{t-1}}+\varepsilon_{t}
$$

where $\alpha_{i}$ is a constant and $\varepsilon_{t}$ is the error term for the sample period from 1990 to 2010. For the European MSCI, index the HAC standard errors-based t-statistics are -0.96 for monthly data and -1.41 for weekly returns and weekly risk free rates, which implies a lack of significant predictive power of the European term structure. The regression results are insignificant for all industry sector indices. To conclude, this trading technique is suitable for exploiting the oil price-based stock return forecasts.

\section{Weekly Returns}

Compared to the daily data, the use of weekly data in the analysis significantly reduces the chance that potential bias may arise, such as the bid-ask effect or problems with non-synchronous trading days. Some authors, 
Arouri \& Nguyen (2010) for example, likewise believe that the monthly data may have some bearing on asymmetry in the responses of stock returns to oil price shocks. The robustness of the results has been verified considering weekly returns. The returns are calculated on Wednesday to avoid Monday and Friday effects. Table 5 summarizes the results of the trading technique using weekly price changes. The trading rule is the same as before and considers weekly FIBOR/EURIBOR as a proxy for risk free rate. The in-sample period for the forecasts is again four years, or 208 weeks.

Table 5: Weekly Returns

\begin{tabular}{|l|c|c|c|c|}
\hline \multicolumn{1}{|c|}{ Index } & Buy (H1) & Sell (H1) & $\alpha$ & $t(\alpha)$ \\
\hline MSCI Eur & 2.79 & -1.41 & 6.45 & 2.88 \\
\hline Oil \& Gas & 2.05 & -0.70 & 4.11 & 1.72 \\
\hline Basic Mat & 2.71 & -0.53 & 5.79 & 2.46 \\
\hline Con Gds & 2.16 & -0.84 & 4.24 & 3.02 \\
\hline Industry & 2.72 & -1.71 & 8.63 & 3.25 \\
\hline Con Serv & 3.42 & -1.78 & 7.38 & 2.36 \\
\hline Health & 2.64 & -0.72 & 5.00 & 2.35 \\
\hline Telecom & 2.08 & -1.23 & 6.52 & 3.02 \\
\hline Utility & 4.14 & -2.06 & 7.51 & 3.24 \\
\hline Financial & 3.17 & -2.69 & 11.18 & 2.25 \\
\hline Tech & 2.10 & -1.67 & 9.40 & \\
\hline
\end{tabular}

For all considered sector stock indices the Jensen's alpha is significant. The index return in periods after a buy signal is also significantly positive. The estimated index return in sell periods is negative, and in many cases significant at a $10 \%$ level. It might be argued, that to forecast the relationship between the weekly returns with higher degree of accuracy, the time series should be tested for the existence of cointegration vectors in the price series, and as appropriate, the prediction should be done using VECM. As mentioned before, if cointegration exists, imposing this restriction will yield more efficient estimates. Within short horizons, however, vector error correction estimates are known to perform poorly relative to those from a VAR (Naka \& Tufte 1997). Because the trading technique is based on one period ahead forecasts, the choice of the $\operatorname{VAR}(p)$ model is more reasonable. To sum up, the oil price-based trading strategy is superior to the buy-and-hold policy not only for monthly returns, but also for the weekly returns. For all industries, the standard deviation of the returns generated by the trading strategy is significantly lower than in the case of the buy and-hold strategy.

Furthermore, to check for the robustness of the empirical results, the additional changes were made to the underlying strategy. First, I divided the dataset into two sub-samples such that both samples have ten year out-ofsample periods (i.e., 1990-2004 and 1996 and 2010). In both cases, the results allow for the same interpretation concerning the favorable risk-return profile. Refining the in-sample period to three or five years similarly leads to no change in the results.

\section{CONCLUSION}

This paper contributes to the literature on the oil and stock price co-movements. It extends the literature analyzing the impact of monthly oil price changes on the European industry sectors related stock indices. In general, some basic results observed for other markets have been observed for the European case. The impact of the oil price changes is significant and varies for different industries. Oil \& gas sector stocks seem to absorb the information from the energy market much faster than do stocks in other industries. For the oil \& gas sector, no Granger causality was observed on a monthly basis, but the instantaneous causality was noted as being highly significant. For monthly data and all price series, no cointegration relationships, i.e., no common stochastic trend could be observed. Studies typically end at this stage of analysis with a statement about significance, power and direction of the relationship between the commodity and stock time series. This paper extends the literature illustrating how to exploit the obtained information for trading strategies. The trading rule based on the simple bivariate $\operatorname{VAR}(p)$ for forecasting future stock returns significantly outperforms the buy-and-hold strategy in term of expected return and risk. The 
systematic risk of the trading strategy is smaller than one and yields large Sharpe ratios. The standard deviation of the strategy is significantly lower than the standard deviation of the market return, a fact which supports the favorable properties of the strategy in comparison to the buy-and-hold policy. The oil-based trading technique provides an additional significant positive Jenson's alpha, as well as significant positive returns in the periods after a buy signal for all indices. For most indices, the index returns after the sell signal are significantly smaller than zero or equal to zero, which implies correct identification of an upward and downward trend by the trading strategy. The results hold for weekly returns as well. Additionally, the robustness of the trading technique construction has been verified, which is a necessary step usually omitted in the literature. In addition to the obvious implication for the market participants, the results contribute to the discussion on the market efficiency. From the EMH point of view, these results question European stock market being efficient in the sense of Jensen (1978). Nevertheless, this paper does not reject the efficient market hypothesis; it is, furthermore, trying to open a discussion on economical exploitability of cross-market linkages. For further research, it is necessary to extend the robustness checks and to consider different time intervals and equity markets.

\section{AUTHOR INFORMATION}

Michael Soucek is a doctoral candidate and research assistant at the department of finance and capital markets at the European University Viadrina in Germany. He graduated in finance and statistics at the Free University Berlin in autumn 2008. His research interests include firm valuation and commodity markets. He was visiting research fellow at the Manchester Metropolitan Business School in the UK and Jönköping International Business School in Sweden. He passed CFA Level I exam. E-mail: soucek@euv-frankfurt-o.de

\section{REFERENCES}

1. Al-Mudhaf, A., \& Goodwin T. (1993). Oil shocks and oil stocks: evidence from the 1970s. Applied Economics, 25, 181-190.

2. Arouri, M. E. H., \& Nquyen, D. K. (2010). Oil prices, stock markets and portfolio investment: Evidence from sector analysis in Europe over the last decade. Energy Policy, 38, 4528-4539.

3. Basher, S. A., \& Sadorsky, P. (2006). Oil price risk and emerging stock markets. Global Finance Journal, 17, 224-251.

4. Driesprong, G., Jacobsen, B., \& Maat, B. (2008). Striking oil: Another puzzle? Journal of Financial Economics, 89, 307-327.

5. Engle, R., \& Granger, C. (1987). Co-integration and error correction: Representation, estimation, and testing. Econometrica, 55, 251-276.

6. Fama, E. (1970). Efficient capital markets: a review of theory and empirical work. Journal of Finance, 25 , 383-417.

7. Ghysels, E., Santa-Clara, P., \& Valkanov, R. (2005). There is a risk-return trade-off after all. Journal of Financial Economics, 76, 509-548.

8. Gisser, M., \& Goodwin, T. (1986). Crude oil and the macroeconomy: tests of some popular notions. Journal of Money, Credit and Banking, 18, 95-103.

9. Hamilton, J. (1983). Oil and the macroeconomy since World War II. Journal of Political Economy, 91, 228-248.

10. Hong, H., Torous, W., \& Valkanov, R. (2007). Do industries lead stock markets? Journal of Financial Economics, 83, 367-396.

11. Hooker, M. (1996). What happened to the oil price-macroeconomy relationship? Journal of Monetary Economics, 38, 195-213.

12. Huang, R. D., Masulis, R., \& Stoll, H. R. (1996). Energy shocks and financial markets. Journal of Futures Markets, 16, 1-27.

13. Jensen, M. (1978). Some anomalous evidence regarding market efficiency. Journal of Financial Economics, 12, 93-330.

14. Johansen, S. (1988). Statistical analysis of cointegration vectors. Journal of Economic Dynamics and Control, 12, 231-254.

15. Johansen, S. (1991). Estimation and hypothesis testing of cointegration vectors in gaussian vector autoregressive models. Econometrica, 59, 1511-1580. 
16. Jones, C., \& Kaul, G. (1996). Oil and sthe stock markets. Journal of Finance, 51, 463-491.

17. Lee, K., Ni, S., \& Ratti, R. (1995). Oil shocks and the macroeconomy: The role of price variability. Energy Journal, 16, 39-56.

18. Lütkepohl, H. (2005). New Introduction to Multiple Time Series Analysis. Springer, Berlin.

19. Mork, K. (1989). Oil and the macroeconomy when prices go up and down: An extension of Hamilton's results. Journal of Political Economy, 97, 740-744.

20. Naka, A., \& Tufte, D. (1997). Examining impulse response functions in cointegrated systems. Applied Economics, 29, 1593-1603.

21. Nandha, M., \& Faff, R. (2008). Does oil move equity prices? A global view. Energy Economics, 30, 986997.

22. Newey, W. K., \& West, K. D. (1987). A simple, positive semi-definite, heteroskedasticity and autocorrelation consistent covariance matrix. Econometrica, 55, 703-708.

23. Oberndorfer, U. (2009). Energy prices, volatility, and the stock market: Evidence from the eurozone. Energy Policy, 37, 5787-5795.

24. Park, C.-H., \& Irwin, S. H. (2007). What do we know about the profitability of technical analysis? Journal of Economic Surveys, 21, 786-826.

25. Park, J., \& Ratti, R. (2008). Oil price shocks and stock markets in the U.S. and 13 European countries. Energy Economics, 30, 2587-2608.

26. Sadorsky, P. (1999). Oil price shocks and stock market activity. Energy Economics, 21, 449-469.

27. Sadorsky, P. (2001). Risk factors in stock returns of Canadian oil and gas companies. Energy Economics, 23, 17-28.

28. Sims, C. A. (1980). Macroeconomics and reality. Econometrica, 48, 1-48. 


\section{NOTES}

